\title{
Repair of sternal dehiscence after bilateral lung transplantation
}

\author{
Demet Karnak, MD, ${ }^{a}$ Sonia S. Shah, MD, ${ }^{\mathrm{b}}$ Maria Solovera Rozas, MD, ${ }^{\mathrm{c}}$ Sudish Murthy, MD, ${ }^{\mathrm{c}}$ Atul C. Mehta, MD, \\ and David P. Mason, MD, ${ }^{\mathrm{c}}$ Ankara, Turkey, and Cleveland, Ohio
}

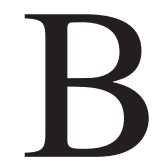

ilateral lung transplantation (BLT) is an accepted treatment for a variety of end-stage pulmonary conditions. The inframammary approach via an anterior thoracotomy and transverse sternotomy, the so-called "clamshell" incision (CSI), is considered a preferable method for BLT owing to adequate exposure of pleural cavities, hila, and heart. The CSI is also used for heart-lung transplantation, bilateral pulmonary metastasectomy, and surgery for congenital cardiac disease. ${ }^{1}$

Transplant recipients carry a variety of comorbidities that could lead to dehiscence, nonunion, or malunion after sternotomy. ${ }^{1} \mathrm{Al}-$ though the terms are overlapping, "sternal dehiscence" (SDH) is defined as total disruption of surgical sutures with or without wound infection. It is also a clinical term used to describe pain, clicking sensation, and instability of the sternum. "Nonunion" is defined as a persistent sternal fracture at least 3 months after surgery or 6 months after trauma without signs of healing or infection. ${ }^{2}$ Deformed or angled healing of the sternum is referred to as "malunion," which can lead to chest wall disfigurement and pulmonary restriction, depending on its severity. Nonunion, malunion, wound infection, and/or broken fixation wires can precede SDH. ${ }^{1,2}$ These complications cause significant morbidity and mortality with reported rates of $34 \%$ and $26 \%$, respectively. ${ }^{1,3}$

We report a case of SDH after CSI for BLT to highlight its impact and early management.

\section{Clinical Summary}

A 43-year-old man with sarcoidosis, pulmonary hypertension, and a body mass index of 28 underwent BLT via a CSI. Anterior thoracotomy was performed through the fourth intercostal space. The sternum was divided transversely. Cardiopulmonary bypass and graft ischemia times were 120 and 300 minutes, respectively. The incision was closed with No. 2 polyglactin 910 (Vicryl) sutures and No. 7 stainless steel sternal wires. He was weaned from the ventilator on the fifth day to be reintubated the next day

From the Department of Chest Diseases, ${ }^{\text {a }}$ Ankara University School of Medicine, Ankara, Turkey, and the Departments of Pulmonary Diseases and Critical Care Medicine ${ }^{\mathrm{b}}$ and Thoracic and Cardiovascular Surgery, ${ }^{\mathrm{c}}$ The Cleveland Clinic Foundation, Cleveland, Ohio.

Demet Karnak, MD, is supported by the National Institutes of Health/ National Cancer Institute (USA) and the Turkish Scientific and Technical Research Council (TUBITAK).

Received for publication March 1, 2006; accepted for publication March 15, 2006.

Address for reprints: David P. Mason, MD, Surgery-Thoracic and Cardiovascular Office G2-132, 9500 Euclid Ave, Cleveland, OH 44195 (E-mail: masond2@ccf.org).

J Thorac Cardiovasc Surg 2006;132:425-6

0022-5223/\$32.00

Copyright $\odot 2006$ by The American Association for Thoracic Surgery doi:10.1016/j.jtcvs.2006.03.016 for hypercapnia. He was extubated on day 10 and discharged on the 29th postoperative day receiving $20 \mathrm{mg}$ of daily prednisone and insulin for chemical diabetes.

On day 37, he reported dyspnea, sternal discomfort, and a popping sensation in his chest. Local tenderness and instability of the sternum were evident. Spirometry revealed severe restriction, values worse than before BLT (Figure 1). A chest x-ray film revealed bilateral parenchymal infiltrates with pleural effusions, evidence of $\mathrm{SDH}$, and fractured sternal wires in the lateral view (Figure 2, A).

At surgical exploration, all the pericostal sutures and sternal wires were ruptured and a small laceration of the epicardium was observed. There was no evidence of infection. The chest was washed out and the thoracotomy reclosed with large-gauge interrupted polypropylene sutures. This allowed for excellent sternal approximation. The sternum was then repaired with a customized plate extending from the manubrium to the xiphoid. The screws were secured in a unicortical fashion to the anterior table. Three months later the chest $\mathrm{x}$-ray film demonstrated resolution of the infiltrates and effusions with the well-aligned sternum (Figure 2, B). The patient reported no discomfort and results of spirometry showed marked improvement (Figure 1).

\section{Discussion}

Nonunion, malunion, pseudoarthrosis, or avascular necrosis of the sternotomy site causing SDH are some of the potential complications that lead to lower forced vital capacity and forced expiratory volume in 1 second after BLT. ${ }^{1}$ Improper healing of the CSI can lead to significant morbidity, particularly after BLT. Clinical signs can be easily recognized, including chest instability with movement or cough. ${ }^{1}$

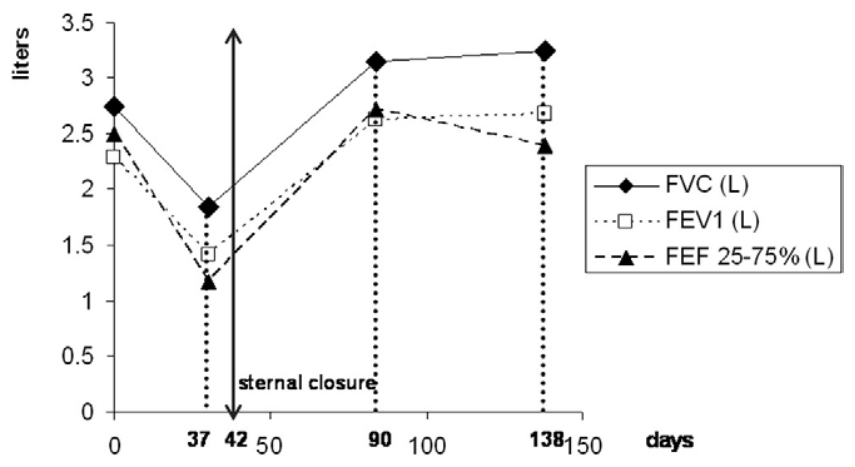

Figure 1. Levels at point 0 on the $x$-axis show pulmonary functions just before the bilateral lung transplantation; other levels represent $30^{\text {th }}, 90^{\text {th }}$, and $138^{\text {th }}$ days of transplantation, respectively. The sternal closure operation is on the $42^{\text {nd }}$ postoperative day. FVC, Forced vital capacity; $F E V_{1}$, forced expiratory volume in 1 second; $F E F$, forced expiratory fraction. 

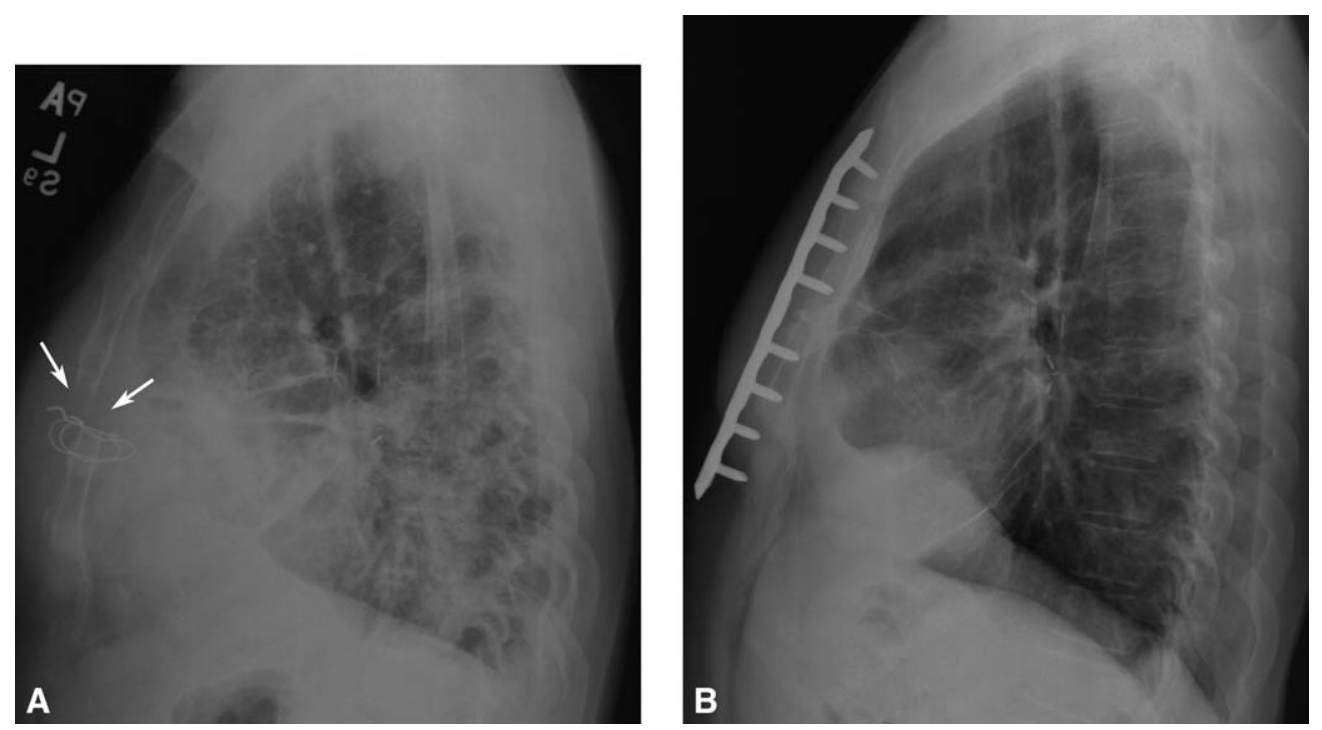

Figure 2. Lateral view of the chest $x$-ray film (A) showing sternal dehiscence and loose fixing wire (arrows) in the post-transplant period; after the sternal closure operation (B) showing intact sternum by locking plate with 8 screws that do not penetrate the posterior sternal table.

SDH can also lead to prolonged need for ventilatory support, mediastinitis, osteomyelitis, and even death (10\%-40\%). ${ }^{4}$ Treatment options are usually surgical, including debridement and fixation with muscle flaps, plates with screws, or cannulated screws with wire. These techniques should be performed in the early postoperative period (4-6 weeks) to prevent mediastinitis, respiratory failure, or bone or tissue destruction. ${ }^{3}$

Lung transplant recipients are at further risk of this complication owing to the potential for prolonged pump time, ventilatory time, and low cardiac output. Prior harvesting of the internal thoracic artery for coronary grafting, radiation therapy, and cardiac massage add to the risk of $\mathrm{SDH} .^{2}$ Obesity can increase chest wall pressure against suture lines. ${ }^{5}$ Our patient had prior steroid use, newly diagnosed diabetes, and obesity contributing to this complication.

In summary, sternal complications are seen in BLT patients in whom the sternum is divided. When chest wall instability exists, reoperation is mandatory. Delay can cause further respiratory embarrassment and make the repair more difficult as the chest wall becomes less mobile. The strategy of surgical repair must focus on both a careful pericostal closure and stabilization of the sternum.

\section{References}

1. Meyers BF, Sundaresan RS, Guthrie T, Cooper JD, Patterson GA. Bilateral sequential lung transplantation without sternal division eliminates posttransplantation sternal complications. J Thorac Cardiovasc Surg. 1999;117:358-64.

2. Wu LC, Renucci JD, Song DH. Sternal nonunion: a review of current treatments and a new method of rigid fixation. Ann Plast Surg. 2005; 54:55-8. Review.

3. Wu LC, Renucci J, Song DH. Rigid-plate fixation for the treatment of sternal nonunion. J Thorac Cardiovasc Surg. 2004;128:623-4.

4. Goldman G, Nestel R, Snir E, Vidne B. Effective technique of sternum closure in high-risk patients. Arch Surg. 1988;123:386-7.

5. Kiessling AH, Isgro F, Weisse U, Moltner A, Saggau W, Boldt J. Advanced sternal closure to prevent dehiscence in obese patients. Ann Thorac Surg. 2005;80:1537-9. 